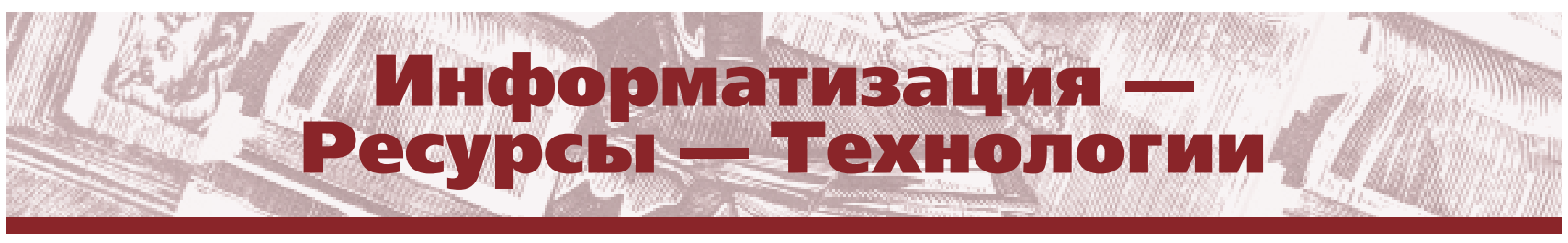

УДК 026.06:004

ББК 78.347 .8 (7Coe)

\title{
T.Е. Савицкая
}

\section{Internet Archive: электронная библиотека нового типа}

Реферат. В статье анализируется деятельность Internet Archive (США) - популярной электронной библиотеки с приоритетом открытого доступа, пионера в области гуманитарного применения передовых информационно-коммуникативных технологий. Internet Archive - часть широкого общедемократического движения за свободу информации в Интернете, сопряженного с инициативами применения лицензии открытого доступа к программному обеспечению, а также передачи обществу авторских прав на продукт творчества с возможностью его дальнейшей доработки.

Дается оценка социальной и культурной значимости планомерного архивирования Сети (копий вебстраниц, видео- и аудиозаписей, новостных телепередач и т. д.) в контексте становления глобальной электронной цивилизации, ориентированной на продвижение скоротечной информации с высоким рейтингом цитирования. Рассматривается новый формат предоставления информационных услуг для глобальной аудитории в сфере цифровой археологии (сервис Archive-It), а также в сфере библиотечного обслуживания (сервис Open Library, электронный каталог-указатель на 23 млн книг из 150 хранилищ). Развитие Internet Archive рассматривается как самобытная стратегия информатизации знания. Дано описание функционирования его основных проектов и сервисов (цифрового книгохранилища, электронного каталога-указателя, медиаколлекции и т. д.) в контексте становления инфраструктуры информационного общества.

Ключевые слова: Internet Archive, электронная библиотека, цифровая археология, свободный доступ к информации.

Для цитирования: Савицкая T.E. Internet Archive: электронная библиотека нового типа // Библиотековедение. 2017. Т. 66, № 1. С. 29-36.

$\mathrm{B}$ 2016 г. широкие круги мировой библиотечной общественности отмечали 20 -летие создания электронной библиотеки Internet Archive (Архива Интернета, США), являющейся не только пионером в сфере гуманитарного применения передовых информационно-коммуникативных технологий, но и доныне - на фоне всемирного бума электронных библиотек - сохраняющей «лица не общее выражение» и мужество в отстаивании собственной стратегии информатизации знания. Помимо печатной продукции Internet Archive собирает копии веб-страниц, видео- и аудиозаписи, а также программное обеспечение, хранит собранный материал и, руководствуясь заявленной миссией организации «всемирного доступа ко всему знанию», предоставляет широкой публике право бесплатного пользования базами накопленных данных.

Некоммерческая, однако, весьма успешная организация, информационная емкость коллекции

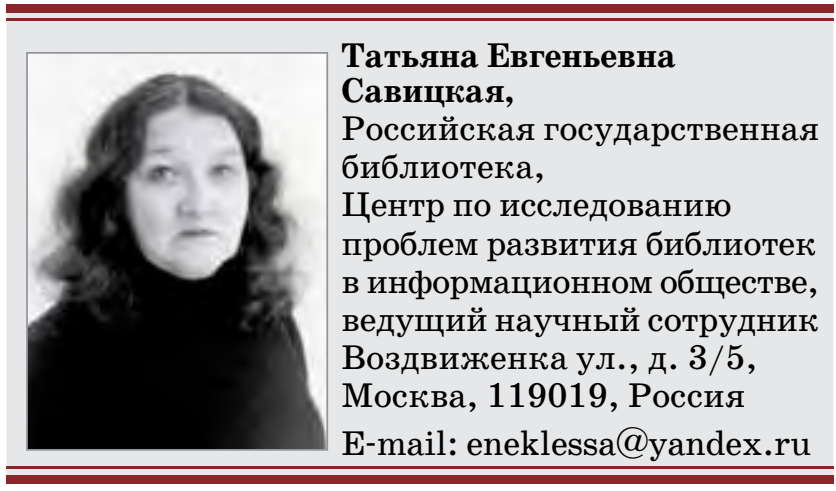

которой к маю 2014 г. приблизилась к 15 петабайтам [1], Internet Archive является частью широкого общедемократического движения за свободу информации в Интернете (Free Culture Movement), coпряженного с инициативами применения лицензий открытого доступа к программному обеспечению (Open Source Movement), а также использования системы «копилефта» ${ }^{1}$ - передачи обществу автор- 
ских прав на продукт творчества с возможностью его дальнейшей доработки. Б. Кейл ${ }^{2}$, учредитель и бессменный директор Internet Archive, - в глазах всемирного сетевого сообщества фигура столь же культовая, как основатель вики-ресурсов, в том числе знаменитой Википедии, Дж. Уэйлс, «сетевой Робин Гуд» А. Шварц ${ }^{3}$ или Л. Лессиг, подаривший миру Creative Commons, гибкую систему распределенных авторских прав. Свидетельство общественного признания - присуждение 23 марта 2010 г. Internet Archive ежегодной премии Free Software Awards, учрежденной некоммерческим фондом Free Software Foundation (FSF) в номинации «Проект социальной взаимопомощи» [2]. В 2015 г. в связи с уходом на пенсию Дж. Биллингтона, более четверти века возглавлявшего Библиотеку Конгресса, на почетный пост директора крупнейшей в США книжной и медиаколлекции представителями библиотечной общественности выдвигался Б. Кейл ${ }^{4}[3]$.

Наряду с проектом «Гутенберг», начало которому еще в 1971 г. положил М. Харт, оцифровавший Декларацию независимости США, Internet Archive (c 1996 г.) - старейшая общедоступная электронная библиотека, живое хранилище демократического потенциала первоначальной киберкультуры с ее этосом солидарности, коммунитарными начинаниями и экономикой дарения. Internet Archive не без успеха отстаивает собственные позиции под напором прагматичной и меркантильной электронной цивилизации удобств и услуг. Вместе с таким ветераном киберкультуры, как Дж. Барлоу $^{5}$, Б. Кейл входит в правозащитную организацию Electronic Frontier Foundation (EFF) ${ }^{6}$. Internet Archive - член Американской библиотечной acсоциации (American Library Association, ALA). В 2005 г. под эгидой Internet Archive был образован Альянс открытого контекста (Open Content Alliance, OCA) - широкий общественный фронт с участием крупнейших компаний (Microsoft, Yahoo!, Amazon), а также целого ряда профессиональных организаций писателей и книгоиздателей, чтобы противодействовать монополии Google на рынке электронных книг.

В 2007 г. штат Калифорния (США) официально присвоил Internet Archive юридический статус библиотеки [4]. Ознакомимся с многогранной деятельностью организации, которая на протяжении многих лет в условиях глобального капитализма с его универсализацией коммерческого принципа выгоды ведет успешную борьбу на новом фронтире гражданских прав - за право доступа к информации [5].

\section{На переднем крае цифровой археологии}

Парадоксальным образом в современную эпоху засилья быстротечной информации не всеми еще осознана культурная значимость планомерного ведения летописи Интернета. Между тем жизненный цикл большинства веб-страниц чрезвы- чайно краток: в 1997 г. он исчислялся 44 днями, в 2003 г. - 100 днями [6]. Проведенный в 2008 г. анализ 2700 цифровых ресурсов показал, что через год $8 \%$ ссылок уже не работало, а через три года таких ссылок было уже $30 \%$. Если учесть взрывообразный количественный и качественный рост Сети (в 1994 г. Интернет исчерпывался приблизительно 3 тыс. веб-сайтов, тогда как в 2014 г. их было свыше миллиарда [6]), очевидным становится масштаб безвозвратно теряемой информации, граничащий с культурной катастрофой. Осознавая плачевные для человечества последствия добровольного заключения в кибернетическом гетто «вечного настоящего», Б. Кейл в беседе с О. Дилинг в январе 2015 г. отметил, что если мы замкнемся только в настоящем, если у нас будет только то, что есть сейчас, что люди хотят знать прямо сейчас без какой бы то ни было истории, то мы станем жить в мире, весьма похожем на мир Оруэлла [7].

Хранение долгосрочной надежной информации - одна из кардинальных основополагающих задач библиотеки как культурного института, которая в современных условиях прогрессирующей интернетизации социума дополняется задачей планомерного архивирования Сети, где первопроходцем выступает как раз руководимая Б. Кейлом институция. Как справедливо замечает Л. Вогэн, Internet Archive - уникальная цифровая библиотека, комбинирующая современную технологию с древней практикой архивирования для хранения международных публично доступных ресурсов неизмеримой значимости [2].

Являясь крупнейшим архивом Сети, за 20 лет работы через сервис Wayback Machine цифровая библиотека сделала доступным для пользователя 435 млрд веб-страниц, а также 6 млн книг общественно доступного профиля, 23 млн книг по каталогу сервиса Open Library, 1,9 млн видео, 2,3 млн аудиозаписей, 668 тыс. новостных телепередач, обширные коллекции старых видеоигр, винтажного программного обеспечения и т. д. [8]. Библиотека располагает четырымя хранилищами данных, 33 центрами сканирования в 8 странах, оцифровывающими по 1,5 тыс. книг в день, и в целях большей надежности сохраняемого материала «зеркалами» в Египте и Амстердаме. Колоссальный объем работы для организации со штатом в 200 человек и скромным годовым бюджетом в 10 млн долл. США, получаемых в основном из благотворительных фондов ${ }^{7}$.

С гордостью именуя себя «цифровым библиотекарем», Б. Кейл в качестве основной цели организации ставит сохранение культурно-исторических ценностей цивилизации в эпоху интернеттехнологий, создание и поддержку электронной библиотеки [9]. Трактовка Интернета как культурного института, контент которого достоин сохранения и изучения, диаметрально противоположна господствующей на рынке поисковых технологий тенденции к продвижению наиболее рейтинговых 
результатов, далеко не всегда соответствующих их подлинной информационной значимости. Лукавое возвеличивание популизма Сети, на котором базируется принцип ранжирования информации по степени ее спрашиваемости, плавно перетекает под флагом радикальной демократизации знания в формат предоставления платных услуг - все более комфортных и комплексных, в «одном флаконе» с пакетом таргетированной рекламы [10]. Работать в разрез с мощным цивилизационным трендом глобального капитализма, отдающим приоритет скоротечной информации, транслирующей влияние моды и рекламы, требует немалого мужества. Борьба Internet Archive с маргинализацией уходящих в небытие культурных смыслов, за преемственность целостных культурно-исторических контекстов по большому счету есть борьба за культуру против коммерциализации знания, превращающей информацию в товар под прикрытием популистских лозунгов. Как выразился Б. Кейл, парадоксально, но, невзирая на взрыв Интернета, мы все еще живем в цифровые темные века [11].

Следует отметить, что такая установка на систематическое архивирование Сети вкупе с открытым доступом к собранному материалу не у всех находит понимание. К. Летару ${ }^{8}$ подвергает критике используемую Internet Archive информационную стратегию за то, что была взята традиционная модель библиотечного архива и перенесена в цифровую эпоху вместо того, чтобы воспользоваться моделью поисковой машины и добавить к ней компонент сохранения [12]. На наш взгляд, рыхлая слоистая структура собранной цифровой коллекции (то, что К. Летару называет «лоскутным подходом») - производное от общественного характера собрания, формируемого во многом за счет спонсорских пожертвований 9 . Некорректно также порицать Internet Archive за то, что в нем недостаточно представлены New York Times, Wall Street Journal и некоторые другие крупные периодические издания, принявшие решение удалить из него свои сайты, поскольку в собственном онлайнархиве ими организован платный доступ к старым изданиям. Так, чтобы получить доступ к статье в New York Times предыдущих лет, нужно заплатить 2,95 долл. США [11].

К. Летару достаточно подробно описывает механизм работы Internet Archive. Он действует в большей степени как традиционный библиотечный архив, нежели современная коммерческая поисковая машина. Вместо того, чтобы быть единым централизованным и стандартизированным предприятием по постоянному сбору информации, его хранилище состоит из миллионов файлов в тысячах коллекций от сотен партнеров, переплетенных между собой и образующих невероятный коллаж, который он соблюдает как хранитель и куратор [12]. Отметим, что организационные принципы социального института, базирующегося на приоритете общественной пользы, не всегда соответствуют критериям оптимальной эффективности и коммерческой целесообразности, непреложным для гигантов IT-индустрии. Его сотрудники осознают, что Internet Archive - не Google, он вовсе не организован прекрасно, и его средства для навигации и поиска богатейшего собранного материала пока еще рудиментарны, но постепенно улучшаются [8].

Структурные параметры формирования данного электронного собрания отображают реализацию его информационных приоритетов - сохранение живого многообразия истории Сети не только как депозита данных для научных ретроспективных исследований, но и как источника удовлетворения образовательных, познавательных, рекреационных и иных нужд широких слоев пользователей. Как образно выразился Э. Рингмар, невзирая на то, что прошлое предстает перед нами как неведомая страна, дружелюбные хранители ее границ из Internet Archive снабжают всех путешествующих бесплатными визами [5].

Известный интерес к архивированию прошлого в начале 2000-х гг. проявляла и мегакорпорация Google. Так, в 2001 г. ею был приобретен архив Usenet (от англ. user network) старейшей сети, предшественницы Интернета, послуживший основой для веб-сервиса Google groups, предоставляющего архивы групп новостей вплоть до 1981 года. В 2006 г. начал работать сервис Google News Archive (на основе купленного PaperofRecord.com), открывающий доступ к отсканированному архиву газет в пределах двухсотлетнего периода. В 2008 г. были расширены временные рамки по оцифровке газет вплоть до самых ранних выпусков. Тем не менее после 2010 г. в связи с недостаточной рентабельностью сопряженных с архивированием прошлого сервисов их функционирование было законсервировано. Амбиции лидера IT-рынка, увлеченного духом дерзкого экспериментирования в сфере робототехники и искусственного интеллекта, растут, приоритеты меняются. Google в 2015 г. сфокусирован на настоящем и будущем [8]. Фактически заморожено дальнейшее развитие громкого проекта Google Book Search - сервиса по снабжению пользователей оцифрованными копиями книг [13].

Поскольку для большого бизнеса в сфере IT-технологий архивирование Сети, как выяснилось, не представляет коммерческого интереса, еще большую общественную значимость приобретает регулярно пополняемая коллекция ретросайтов Internet Archive, располагающего веб-сканами, начиная с 1984 года. Согласно информации на сайте библиотеки, на протяжении последних лет объемы архивируемых веб-страниц росли едва ли не в геометрической прогрессии. Если в 2005 г. Internet Archive располагал всего лишь 40 млрд веб-страниц, то в 2010 г. их было уже 150 млрд, а в 2014 - свыше 400. По состоянию на август 2016 г. содержится 502 млрд копий веб-страниц [14]. Закономерно, что именно на базе этой организации с 2001 г. работает 
Международный семинар архивирования Интернета (The International Web Archiving Workshop) для обмена опытом, а с 2003 г. - Международный консорциум по сохранению Интернета (International Internet Preservation Consortium), который занимается разработкой стандартов и курирует создание программного обеспечения с открытым исходным кодом [15]. Ознакомимся вкратце с динамикой развития и основными структурными подразделениями Internet Archive.

\section{Internet Archive: сервисы и проекты}

Если бы вся деятельность Internet Archive сводилась к использованию сетевой машины времени, фиксирующей содержание веб-страниц с помощью бота с сохранением их в онлайн-режиме, знаменитой Wayback Machine ${ }^{10}$, вряд ли ему удалось сохранить роль лидера в формировании институциональной парадигмы общедоступной электронной библиотеки. Более чем за 20 лет активной деятельности, оставаясь крупнейшим публично доступным и частным образом финансируемым цифровым архивом в мире [15], «свободная библиотека» сформировала обширный пакет специальных проектов, продвигающих новый формат предоставления информационных услуг для глобальной аудитории. С 2006 г. начал работать сервис Archive-It, дающий возможность по подписке формировать собственные цифровые архивы как организациям, так и индивидуальным пользователям. К марту 2014 г. Archive-It обслуживал 275 институтов-партнеров из 46 штатов США, а также из 16 стран, в результате чего было архивировано 7,4 млрд URL для 2444 общественных коллекций. В их числе - библиотеки университетов (в том числе Стэнфордского, Колумбийского, Американского университета в Каире), Национальная библиотека Австралии, публичные библиотеки, государственные архивы (например, Государственный архив Северной Каролины), федеральные институты и музеи [16].

Весьма представительная коллекция текстов Internet Archive, согласно информации на сайте, насчитывала к 2 июня 2016 г. 10021169 ед. хр., к 27 ноября 2015 г. - 6563945 англоязычных текстов, 358721 - на французском языке, 344810 на немецком, 134170 - на испанском, 84147 - на китайском (представлены также тексты на арабском, датском, португальском, русском и японском языках) [17]. Если учесть, что суммарно в июле 2013 г. коллекция насчитывала 4,4 млн книг (при ежемесячном распространении 15 млн копий), а в ноябре 2008 г. не превышала одного миллиона, налицо чрезвычайно позитивная динамика роста. Источники пополнения коллекции разнообразны: помимо оцифровки текстов в 33 центрах самого Internet Archive, высокий общественный престиж библиотеки, приоритетом которой является некоммерческий доступ к базам данных, способствует ее расширению через дарение. Так, в 2008 г., после завершения проекта Live Search Books корпорация Microsoft безвозмездно передала Internet Archive 300 тыс. цифровых копий и оборудование для сканирования (по специальной договоренности оцифровка источников производилось самим Internet Archive). K ноябрю 2013 г. библиотека располагала 900 тыс. электронных копий общественно доступных книг, полученных от Google Book Search стараниями «цифрового партизана» А. Шварца, принципиального противника частной собственности на информацию [18].

Открытая библиотека (Open Library) - другой некоммерческий проект Internet Archive, осуществляемый при поддержке Калифорнийского государственного университета и семейного Кейл/ Остин фонда. Он предоставляет пользователям электронный каталог-указатель на 23 млн книг из 150 хранилищ (с возможностью поиска по авторам, названиям сочинений и издательствам), полнотекстовый доступ к 1 млн 600 тыс. книг общественного профиля, а также к 250 тыс. недавно изданных электронных книг в сотрудничестве с 1 тыс. библиотек-партнеров из 6 стран [19]. Internet Archive располагает также собственной библиотекой электронных книг (The Internet Archive Lending Library), насчитывающей 12 тыс. ед. хранения.

Осознавая культурную значимость составления цифровых коллекций, еще в 2004 г. Б. Кейл отметил, что следует сохранять все, достойное быть сохраненным: все книги, все кинофильмы, всю музыку, программное обеспечение, веб-страницы [6]. Итог многолетних кропотливых усилий на ниве собирательства - колоссальный архив цифровых медиа, содержащий 3863 полнометражных фильма; классические мультфильмы; виртуальную артгалерею (880 тыс. ед. хр. от Metropolitan Museum of Art, Cover Art Archive и т. д.); рекламные объявления; любительское и домашнее видео; изображения, по специальному соглашению предоставленные NASA (в 2012 г. они составляли 100 тыс. ед. хр.); 160 тыс. микрофильмов; тематические подборки разноплановых видеоматериалов; обширный телевизионный архив и т. д. [8; 9].

Одна из наиболее быстрорастущих коллекций Internet Archive - собрание новостей с 65 зарубежных и американских телеканалов, пополняемое 24 часа в сутки 7 дней в неделю, начиная с 2000 года. В 2013 г. коллекция теленовостей была существенно расширена, когда М. Метелитс передал в дар архив матери, М. Стокс, содержащий записи новостных передач в Бостоне и Филадельфии за 35 лет [1]. Обширная аудиоколлекция Internet Archive содержит аудиокниги (включая более 70 тыс. от LibriVox ${ }^{11}$ ), новостные радиопередачи, старые радиошоу (в том числе 1,7 млн радиопередач, лицензированных по Creative Commons), «Жиивой музыкальный архив» (40 тыс. концертных записей как популярных, так и малоизвестных музыкантов) [8; 20]. 
Уникально собрание старого программного обеспечения (ПО) в Internet Archive, хранящего для пользователя живую историю развития киберкультуры на протяжении последних 50 лет: составленная Дж. Скоттом коллекция винтажного ПО на CD-ROM, начиная с эры $\mathrm{BBS}^{12}$ [21]; условно-бесплатные (share-ware) программы, диски, старые сайты; компьютерные газеты и журналы. Широкий резонанс вызвало предоставление пользователям в 2013-2014 гг. старых компьютерных игр, эмулированных к современным компьютерам в проекте MESS с использованием Javascript: классических аркадных игр и MS-DOS (более 2300 штук), игр для Atari (2600 штук) и Commodore (64 штуки), а также игр для различных приставок [8; 21]. Стремясь приобщить к электронной информации все категории населения, Internet Archive использует два библиомобиля передвижные цифровые библиотеки с выходом в Интернет через спутник, один из которых курсирует по США, а второй - по Египту и Уганде [22].

Неуклонный рост числа пользователей - закономерная награда интенсивно развивающегося ресурса. По данным на декабрь 2016 г. общее число пользователей Internet Archive составляло 2987411 человек. Если за июль 1996 г., на заре развития проекта, к нему присоединилось всего 16 пользователей, то, например, в декабре 2005 г. число новых посетителей составило уже 14794 человека, а в ноябре 2016 г. - и вовсе 50505 человек [23]. В декабре 2016 г. проект модерировал 372 форума, общее число постов составляло 453827 [23].

Осознавая растущее значение Сети как зоны социально-культурного творчества, Internet Archive интенсивно развивается, расширяя список партнеров, пакет проектов и программ, обслуживая свыше миллиона посетителей в день в соответствии со своим девизом: «Все знание для всех везде и всегда - бесплатно».

\section{Примечания}

1 Популярный неологизм «копилефт» (англ. copyleft), известный также как «авторское лево», является антонимом общепринятого наименования «копирайт» (copyright) и обозначается символом в круге, повернутым в левую сторону, в отличие от распространенного символа копирайта, а также надписью Copyleft - All rights reversed ( «Копилефт - все права отменены»).

2 Брюстер Кейл (Brewster Kahle, p. 22.10.1960) американский программист и интернет-предприниматель, выпускник Массачусетского технологического института, соучредитель WAIS (Wide Area Information Servers) и Alexa Internet, член Американской академии наук и искусств. Входит в состав консультативного совета по кибернетической инфраструктуре при National Science Foundation. В 2012 г. введен в Зал славы Интернета.

3 Аарон Шварц (Aaron Swartz, 18.11.198611.1.2013) - американский программист и интернет- активист, член рабочей группы RDF в Консорциуме Всемирной Сети, создатель сервиса Infogami (ныне в составе сайта Reddit), соучредитель правозащитного движения против интернет-цензуры Demand Progress. Получил широкую известность как борец против продвигаемой правительством США законодательной инициативы SOPA (Stop Online Piracy Act). В 2011 г. А. Шварц, соавтор «Партизанского манифеста об открытом доступе» (Guerilla Open Access Manifesto), предпринял массированное скачивание научной информации из онлайновой библиотеки JSTOR в MIT с целью сделать ее общедоступной. Будучи подвергнут судебному преследованию, покончил с собой на двадцать седьмом году жизни.

4 «Я был бы польщен», - отреагировал Б. Кейл на инициативу общественности. Однако 27 февраля 2016 г. Барак Обама выдвинул на пост директора Библиотеки Конгресса афроамериканку Карлу Хейден, возглавляющую библиотеку в Мериленде. 5 Джон Барлоу (John Barlow, p. 1947) - американский поэт, эссеист, интернет-активист и правозащитник, вице-президент Electronic Frontier Foundation, автор стяжавшей громкую популярность Декларации независимости киберпространства.

6 Electronic Frontier Foundation (Фонд электронных рубежей) - основанная в июле 1990 г. в США некоммерческая правозащитная организация для отстаивания конституционных прав личности в контексте новых угроз, порожденных электронной эрой.

7 Начало Internet Archive положили 15 млн долл. США, вырученные Б. Кейлом после продажи AOL разработанной им поисковой системы WAIS. К числу финансовых спонсоров Internet Archive относится, наряду с известными благотворительными фондами (Sloan Foundation, Andrew W. Mellon Foundation и т. д.), грантами и пожертвованиями, семейный фонд Kahle/Austin Foundation, образованный Б. Кейлом и его супругой Мэри Остин.

8 Калев Летару (Kalev Leetaru) - аналитик из исследовательского центра компании Yahoo! при университете Джорджтауна (США).

9 На сайте Internet Archive ведется подробный учет единиц хранения, а также целых коллекций, предоставленных спонсорами (Microsoft, Библиотека Конгресса, Смитсоновский институт, благотворительные фонды, частные корпорации, университетские библиотеки, отдельные жертвователи).

10 Wayback Machine, изобретенная Б. Кейлом и Б. Джильетом (Bruce Gilliat), используется как веб-сервис с 2001 года. В названии обыгрывается аллюзия на «WABAC machine» из мультфильма «Роки и Бульвинкль», с помощью которой в одном из эпизодов мистер Пибоди и Шерман перемещаются во времени, желая быть свидетелями и участниками исторических событий.

11 LibriVox - некоммерческий проект по созданию аудиокниг, распространяемых как общественное достояние.

12 Bulletin Board System (BBS) - электронная доска объявлений, способ общения пользователей через коммутируемые телефонные сети, дающий доступ помимо сводки новостей к тематическим конференциям и каталогам обмена файлами. 


\section{Список источников}

1. Brownell Br., Hansen-Bundy B. Meet the People Behind the Wayback Machine, One of Our Favorite Things About the Internet [Электронный pecypc]. URL: http://www.motherjones.com/media/2014/05/ internet-archive-wayback-machine-brewster-kahle (дата обращения: 20.03.2016).

2. Thelwall M., Vaughan L. A Fair History of the Web? Examining Country Balance in the Internet Archive [Электронный pecypc]. URL: https://pdfs. semanticscholar.org/4e32/f5394ff38ee2d4e56a2709 $52 \mathrm{db} 902 \mathrm{becfd5e.pdf}$ (дата обращения: 22.03.2016).

3. Gillmor D. The Creator of the Internet Archive Should Be the Next Librarian of Congress [Электронный pecypc]. URL: http://www.slate.com/blogs/future tense/2015/09/10/brewster_kahle_creator_of_the_ internet_archive_should_be_the_next_librarian. $\mathrm{html}$ (дата обращения: 10.02.2016).

4. Internet Archive Officially a Library [Электронный pecypc]. URL: http://blog.archive.org/2007/06/25/ internet-archive-officially-a-library/ (дата обращения: 12.03.2016).

5. Ringmar E. Liberate and Disseminate [Электронный pecypc]. URL: http://ringmar.net/index. php/2008/04/05/liberate-and-disseminate/ (дата обращения: 15.03.2016).

6. Lafrance A. Raiders of the Lost Web [Электронный pecypc]. URL: http://www.theatlantic.com/ technology/archive/2015/10/raiders-of-the-lostweb/409210/ (дата обращения: 28.02.2016).

7. Dilling $A$. In an Old Church, the Internet Archive Stores Our Digital History [Электронный pecypc]. URL: http://kalw.org/post/old-church-internetarchive-stores-our-digital-history\#stream/0 (дата обращения: 22.03.2016).

8. Never Trust a Corporation to Do a Library's Job [Электронный ресурc]. URL: https://medium.com/ message/never-trust-a-corporation-to-do-a-librarysjob-f58db4673351\#.dgxp5razb (дата обращения: 15.03.2016).

9. Internet Archive Projects [Электронный pecypc]. URL: https://archive.org/projects/ (дата обращения: 23.03.2016).

10. $\operatorname{Carr} N$. The Library of Utopia [Электронный реcypc]. URL: https://www.technologyreview. com/s/427628/the-library-of-utopia/ (дата обращения: 23.03.2016).

11. Womack D. Who Owns History? [Электронный pecypc]. URL: http://www.cabinetmagazine. org/issues/10/womack.php (дата обращения: 10.03.2016).
12. Leetaru $K$. The Internet Archive Turns 20. A Behind the Scenes Look at Archiving the Web [Электронный pecypc]. URL: http://www.forbes.com/sites/ kalevleetaru/2016/01/18/the-internet-archiveturns-20-a-behind-the-scenes-look-at-archiving-theweb/\#2f1cb89a7800 (дата обращения: 25.03.2016).

13. Eastman D. Google Books Reduces Its Digitizing and Preservation of Old Books While Internet Archive Increases Its Efforts at the Same Thing [Электронный pecypc]. URL: https://blog.eogn.com/2015/03/28/ google-books-reduces-its-digitizing-and-preservationof-old-books-while-internet-archive-increases-itsefforts-at-the-same-thing/ (дата обращения: 28.03.2016).

14. Internet Archive [Электронный ресурс]. URL: https://archive.org/about/bios.php (дата обращения: 22.11.2016).

15. Internet Hall of Fame [Электронный pecypc]. URL: http://www.internethalloffame.org/inductees/ brewster-kahle (дата обращения: 30.03.2016).

16. Praetzellis $M$. What's the Difference between the General Archive and Archive-It? [Электронный pecypc]. URL: https://support.archive-it.org/hc/en-us/ articles/209783963-What-s-the-difference-betweenthe-General-Archive-and-Archive-It- (дата обращения: 20.02.2016).

17. Internet Archive Search: Mediatype: Texts [Электронный pecypc]. URL: https://archive.org/search. php?query=mediatype \% 3Atexts (дата обращения: 12.11.2016).

18. Kahle B. Aaron Swartz Memorial at the Internet Archive [Электронный pecypc]. URL: https:// archive.org/details/AaronSwartzMemorialAtTheIn ternetArchive (дата обращения: 10.03.2016).

19. In-Library eBook Lending Program Expands to 1000 Libraries [Электронный pecypc]. URL: http://www. blog.archive.org/2011/06/25/ (дата обращения: 12.03.2016).

20. Internet Archive [Электронный ресурc]. URL: http:// www.archiveteam.org/index.php?title=Internet_ Archive (дата обращения: 15.03.2016).

21. Scott J. Change Computer History Forever: Well, Here We Are [Электронный pecypc]. URL: http:// ascii.textfiles.com/archives/3947 (дата обращения: 17.03.2016).

22. Lepore J. The Cobweb: Can the Internet be Archived? [Электронный ресурc]. URL: http://www.newyorker. com/magazine/2015/01/26/cobweb (дата обращения: 10.03.2016).

23. Users Statistics [Электронный pecypc]. URL: http:// archive.org/about/stats.php (дата обращения: 27.10.2016). 


\title{
Internet Archive: Digital Library of a New Type
}

\author{
Tatiana E. Savitskaya, \\ The Russian State Library, 3/5 Vozdvizhenka Str., Moscow, 119019, Russia \\ E-mail: eneklessa@yandex.ru
}

\begin{abstract}
The article examines the activities of the Internet Archive (USA), popular e-library with open access priority, a pioneer in the field of humanitarian applications of the advanced information and communication technologies. Internet Archive - is a part of broader democratic movement for the freedom of information on the Internet, coupled with the initiatives of the use of open access license to the software, as well as the transfer to the society of the copyright for creative product with the possibility of its further development.

There is analyzed the social and cultural importance of systematic archiving of the Web (copies of web pages, video and audio recording, TV news, etc.) in the context of formation of the global electronic civilization, focused on the promotion of transient data with a high citation rating. There is considered the new format of providing information services to the global audience in the field of digital archeology (Archive-It service), as well as in the field of library services (Open Library service, an electronic catalog-pointer to 23 million books from over 150 repositories).

The development of the Internet Archive is considered as the original strategy of informatization of knowledge; there is described the operation of its core projects and services (digital book repository, electronic pointer catalog, media collection, etc.) in the context of infrastructure development of the Information Society.
\end{abstract}

Key words: Internet Archive, Digital Library, Digital Archeology, Free Access to Information.

Citation: Savitskaya T.E. Internet Archive: Digital Library of a New Type, Bibliotekovedenie [Library and Information Science], 2017, vol. 66, no. 1, pp. 29-36.

\section{References}

1. Brownell Br., Hansen-Bundy B. Meet the People Behind the Wayback Machine, One of Our Favorite Things About the Internet. Available at: http:// www.motherjones.com/media/2014/05/internetarchive-wayback-machine-brewster-kahle (accessed 20.03.2016).

2. Thelwall M., Vaughan L. A Fair History of the Web? Examining Country Balance in the Internet Archive. Available at: https://pdfs.semanticscholar.org/4e32/ f5394ff38ee $2 d 4$ e56a270952db902becfd5e.pdf (accessed 22.03.2016).

3. Gillmor D. The Creator of the Internet Archive Should Be the Next Librarian of Congress. Available at: http:// www.slate.com/blogs/future_tense/2015/09/10/ brewster_kahle_creator_of_the_internet_ archive_should_be_the_next_librarian.html (accessed 10.02.2016).

4. Internet Archive Officially a Library. Available at: http://blog.archive.org/2007/06/25/internetarchive-officially-a-library/ (accessed 12.03.2016).

5. Ringmar E. Liberate and Disseminate. Available at: http://ringmar.net/index.php/2008/04/05/liberateand-disseminate/ (accessed 15.03.2016).

6. Lafrance A. Raiders of the Lost Web. Available at: http://www.theatlantic.com/technology/ archive/2015/10/raiders-of-the-lost-web/409210/ (accessed 28.02.2016).

7. Dilling A. In an Old Church, the Internet Archive Stores Our Digital History. Available at: http://kalw. org/post/old-church-internet-archive-stores-ourdigital-history\#stream/0 (accessed 22.03.2016).

8. Never Trust a Corporation to Do a Library's Job. Available at: https://medium.com/message/never-trusta-corporation-to-do-a-librarys-job-f58db4673351\#. dgxp5razb (accessed 15.03.2016).

9. Internet Archive Projects. Available at: https:// archive.org/projects/ (accessed 23.03.2016).

10. Carr N. The Library of Utopia. Available at: https:// www.technologyreview.com/s/427628/the-libraryof-utopia/ (accessed 23.03.2016).

11. Womack D. Who Owns History? Available at: http:// www.cabinetmagazine.org/issues/10/womack.php (accessed 10.03.2016).

12. Leetaru K. The Internet Archive Turns 20. A Behind the Scenes Look at Archiving the Web. Available at: http:// www.forbes.com/sites/kalevleetaru/2016/01/18/ the-internet-archive-turns-20-a-behind-the-sceneslook-at-archiving-the-web/\#2f1cb89a7800 (accessed 25.03.2016).

13. Eastman D. Google Books Reduces Its Digitizing and Preservation of Old Books While Internet Archive Increases Its Efforts at the Same Thing. Available at: https://blog.eogn.com/2015/03/28/google-booksreduces-its-digitizing-and-preservation-of-old-bookswhile-internet-archive-increases-its-efforts-at-thesame-thing/ (accessed 28.03.2016).

14. Internet Archive. Available at: https://archive.org/ about/bios.php (accessed 22.11.2016). 
15. Internet Hall of Fame. Available at: http://www. internethalloffame.org/inductees/brewster-kahle (accessed 30.03.2016).

16. Praetzellis M. What's the Difference between the General Archive and Archive-It? Available at: https:// support.archive-it.org/hc/en-us/articles/209783963What-s-the-difference-between-the-General-Archiveand-Archive-It- (accessed 20.02.2016).

17. Internet Archive Search: Mediatype: Texts. Available at: https://archive.org/search. php?query=mediatype $\%$ 3Atexts (accessed 12.11.2016).

18. Kahle B. Aaron Swartz Memorial at the Internet Archive. Available at: https://archive.org/details/AaronSwartz MemorialAtTheInternetArchive (accessed 10.03.2016).
19. In-Library eBook Lending Program Expands to 1000 Libraries. Available at: http://www.blog.archive. org $/ 2011 / 06 / 25 /$ (accessed 12.03.2016).

20. Internet Archive. Available at: http://www.archive team.org/index.php?title=Internet_Archive (accessed 15.03.2016).

21. Scott J. Change Computer History Forever: Well, Here We Are. Available at: http://ascii.textfiles.com/ archives/3947 (accessed 17.03.2016).

22. Lepore J. The Cobweb: Can the Internet be Archived? Available at: http://www.newyorker.com/ magazine/2015/01/26 (accessed 10.03.2016).

23. Users Statistics. Available at: http://archive.org/ about/stats.php (accessed 27.10.2016).

\section{Обязательный электронный экземпляр печатных изданий: система приема, обработки, хранения и учета}

С 1 января 2017 г. в Российскую государственную библиотеку (РГБ) поступают в электронном виде обязательные экземпляры всех печатных изданий, выходящих в нашей стране. Этот процесс осуществляется согласно Федеральному закону № 278-ФЗ от 3 июля 2016 г. «О внесении изменений в Федеральный закон № 77-Ф3 от 9 декабря 1994 г. “Об обязательном экземпляре документов”" .

Теперь издатели должны предоставлять один экземпляр печатных изданий в электронной форме, заверенный электронной подписью, в Информационное агентство России «ТАСС» и РГБ для постоянного хранения.

Специально для того, чтобы сделать передачу обязательного электронного экземпляра максимально простой и удобной для издателей, на портале РГБ была создана Система приема обязательных экземпляров печатных изданий в электронной форме. Зарегистрировавшись, издатели могут через личный кабинет производителя документов загружать электронную копию оригинал-макета в систему.

Подробнее на сайте: http://www.rsl.ru/ru/news/261216/

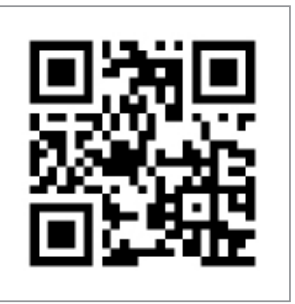

